\title{
Workplace Learning Cultures, Learning Potential and Important Work Outcomes among Managerial Employees in Five-Star Turkish Hotels
}

\author{
Kadife Koyuncu (Çanakkale Onsekiz Mart University, Turkey) \\ Dr. Bekir Esitti (Çanakkale Onsekiz Mart University, Turkey) \\ Prof. Dr. Ronald J Burke (York University, Canada) \\ Prof. Dr. Mustafa Koyuncu (Çanakkale Onsekiz Mart University, Turkey)
}

\begin{abstract}
This research investigated the relationship of perceived workplace learning culture, workplace learning potential, perceived employability, feelings of psychological empowerment, important work outcomes, and selfreported assessments of service quality among supervisors and managers in five star hotels in Turkey. Data were collected from 205 managers, an eighty-nine percent response rate, from twelve hotels, using anonymously completed questionnaires. Work outcomes included job satisfaction, perceptions of service quality and intent to quit. Managerial Self-efficacy was significantly related to perceptions of workplace learning culture, opportunities for learning, employability and all other work outcomes. In addition, stronger workplace learning cultures and more opportunities for learning also had positive effects of several work outcomes.

The present research has limitations which should be noted to better assess the results. First, all data were collected using self-report questionnaires with the possibility of response set tendencies and common method biases. Second, all data were collected at one point in time making it challenging to address issues of causality. Third, although the sample was relatively large, all respondents came from high quality properties in only one large city in Turkey (Istanbul), thus the extent to which our findings would apply to hotels in other regions or hotels of lower quality is indeterminate.

Practical implications include training supervisors on ways to develop and support a workplace learning culture, training all employees on the benefits of personal efficacy and ways to increase it, and training employees on the benefits of their own learning and ways to enhance this.
\end{abstract}

\section{Introduction}

This study examined the relationship of workplace learning culture, opportunities and sources of workplace learning, self-perceptions of employability, important work outcomes such as job satisfaction, feelings of empowerment, quality of service provided, and intentions to quit among managers working in five- star hotels in Turkey. The motivation and performance of these employees are significant factors in hotel effectiveness and success (Kusluvan, 2003; Kusluvan, 2003; Kusluvan, et. al, 2012).

Interestingly, workplace learning cultures, staff empowerment and staff employability may even play a larger role in the performance of hospitality organizations given both the negative images and the negative realities of working in this sector such as low pay, routine jobs, long work hours, uncaring supervision, unpleasant working conditions, limited career advancement, and high levels of staff turnover (Baum, 2007; Kusluvan, et. al, 2012).

The hospitality and tourism sector in Turkey

The tourism and hospitality sector is a major and growing contributor to the Turkish economy (Duman and Tosun, 2010; Gokovali, 2011). The tourism and hospitality sector has been shown to be significant contributor to economic growth in Turkey as a whole (Gunduz and Haemi-J, 2005). Turkey ranks in the top ten countries in the world in both numbers of tourists and tourism revenues. Thus providing high quality service and experiences is important not only to continuing and increasing success in an increasingly competitive environment, but also as a significant contributor to the economic fortunes of Turkey as a whole.

Service quality

Service quality has been found to be is a major factor in the success of organizations in the hospitality and tourism sector (Zemke and Schaaf, 1989; Bowen and Lawler, 1995). Organizational cultures and climates that foster high levels of service quality include several features such as managerial leadership, giving high priority to human resource management policies and practices, providing staff training and development opportunities, and encouraging staff to help each other perform their jobs (Kusluvan, et. al, 2012).

Review of the literature

Organizational learning

Researchers and writers have discussed the role that organizational learning plays in organizational success (Salas and Von Glinow, 2008, Wilhelm, 2006). But organizations do not learn, individuals within organizations learn. All organizational learning then results from the learning of individuals (Argyris, 2003, 1997). As a consequence, organizations that support and encourage employee workplace learning will derive benefits 
(Denton, 1998; Teare, 19978; Teare and Rayner, 2002). Learning and knowledge creation become a competitive advantage (Nonaka 1991).

Learning in organizations takes place at all levels. Li, et. al, (2011) document ways that newly appointed hotel general managers lean how to manage their hotels, Magnini (2009) illustrates how expatriate hotel employees learn how to function in new countries and cultures, and Doyle, et. al, (2012) show how people in low level front lie service jobs engage in informal workplace learning.

\section{Workplace learning cultures}

Some organizations are learning organizations, possessing learning cultures. Human resource development policies and practices have a central role to play in the development and support of a workplace learning culture. Marsick and Watkins (2003) suggest that informal learning occurs across three levels: individual, work team, and organizational. They developed a measure of the learning organizational cultures having seven dimensions and by 2003 had collected data from over 200 organizations using their measures. They reported that these dimensions predicted organization outcomes such as knowledge and financial performance. We use a shortened version of their measures in our investigation.

Lopez, et. al, (2005), in a study of 195 Spanish firms employing 200 or more employees found that high performance human resource management practices (e.g., hiring, training, compensation, employee participation efforts) increased levels of organizational learning, which in turn had a positive effect on three indirect measures of business financial performance.

Law and Ngai (2008), in a study of 134 firms in manufacturing and wholesale retail operations in Hong Kong, reported higher levels of firm performance in firms indicating higher levels of knowledge sharing and learning behaviors.

Creating a workplace learning culture is particularly relevant for the hospitality and tourism sector on at least three fronts. First, the bulk of their workforces tends to be relatively young, new to their jobs, and having the potential for high levels of turnover. A workplace learning culture would help these relative newcomers master their jobs in a more timely fashion. A workplace learning culture might also interest these employees in other more responsible and higher level jobs cutting down turnover. Finally, development and support of a workplace learning culture could address some of the common negatives in the hospitality sector such as routine jobs, limited upward mobility, and poor supervision.

\section{Learning potential of workplaces}

Ideally, individuals can learn throughout their working and non-working lives. Such learning benefits individuals and organizations. Individuals remain productive and adaptable in their jobs, increase their prospects for both internal mobility and promotion and their employability with other organizations; organizations remain successful in an increasingly competitive international marketplace. There is also increasing pressure on individual and learning as new knowledge and fast changing technologies appear.

Much work-based learning occurs informally and takes place with workplaces. Individuals can learn by observing others, by taking with others, by reflecting on one's work experiences and results, and from advice from one's supervisors. Workplace learning has generally been unplanned.

Nikolova, et. al, (2014) propose and develop a measure of two types of potential work-based learning: interactional resources from others (from colleagues, from supervisors) and task-based learning (from reflection and from experimentation). We use their measures in this study.

Employability

One individual and organizational by-product of workplace learning is increased employability on the part of individual employees. Rothwell and Arnold (2007, p.25) define employability as

"The individual's ability to keep the job one has, and of getting job ones desires". One of the consequences of work-based learning by individuals is that they acquire attitudes, behaviors, skills and knowledge reflected in a high likelihood of their retaining their jobs and advancing their careers both inside and outside their current workplaces (van der Heijde and van der Heijden 2006). Employability helps individuals remain successful in their jobs and careers and contributes to organizational success (van der Heijden, et. al,, 2009). Highly employable individuals help their organizations respond to job changes and increasing demands for new products and services. Some workplaces are more supportive of worker employability than are others (Nauta, et. al, 2009). Employability has been found to be related to objective career success for early career employees and to number of promotions for late career employees (van der Heijden, et. al, 2009). In a study of 215 Dutch nonacademic university staff both informal and formal learning opportunities increase employability.

Van Dam (2004), in a study of 339 employees at various levels of a Dutch bank, found that employability orientation was positively related to openness, initiative, and a managerial career anchor and negatively related to tenure, continuance commitment, and technical competence and security career anchors. Employability orientation, not surprisingly was a strong predictor of employability activities (e.g., keeping informed of internal job openings, managing one's career, engaging in developmental activities). 
Wittekind, et. al, (2010), in a longitudinal study of 465 employees form four companies in Switzerland, reported that education, support for career and skill development, current level of job-related skills, and willingness to change jobs were significant predictors of perceived employability; however willingness to develop new competencies, opportunity awareness and self-presentation skills had no relationship with perceived employability.

But there may also be a downside to increasing managerial employability. De Cuyper and De Witte (2011) consider what they term "the management paradox"; high levels of employability will be associated with greater employee intentions to quit and seek employment elsewhere, so why increase employee employability? Interestingly, self-reported employability was found to be positively related to higher levels of organizational commitment and individual performance in a study of 551 workers in Belgium.

\section{Self-efficacy}

It has been suggested that some individuals are more likely to take advantage of possibilities associated with opoortunhi9ttes for learning and growth and interest in increasing their employability. One individual differences characteristic likely to be relevant here is the concept of self- efficacy. Maddux (2002, p.270) defines selfefficacy as "what I believe I can do with my skills under certain conditions". If people believe they can produce desired outcomes through their actions they will persevere despite obstacles. Stajkovic and Luthans (1998), in a meta-analysis of 114 studies having 157 samples, $(n=21,616)$ found a significant correlation between selfefficacy and a variety of work-related perforce outcomes. Others (Luszczynska, et. al, 2005; Luszczynska, et. al, 2005) have reported positive associations of self-efficacy and a variety of favorable well-being outcomes in a number of different countries as well.

\section{The present study}

In this study, we consider the relationship of employee perceptions of the presence of a workplace learning culture, potential sources of their learning, benefits of any such learning to their employability levels of felt psychological empowerment, important work outcomes (job satisfaction, intent to quit), and assessments of quality of service provided to guests and clients.

We examine the following general hypotheses.

1. Personal demographic characteristics, including self-efficacy, will be associated with perceptions of workplace learning culture, potential sources of workplace learning, and various work outcomes.

2. Workplace learning culture and potential sources of workplace learning will be positively associated selfreported employability, with psychological empowerment, job satisfaction, and assessments of service quality provided to clients and negatively associated with intention to quit.

\section{Method}

\subsection{Procedure}

Data were collected using anonymously completed questionnaires from full-time employees working in managerial positions in twelve five-star hotels in Istanbul Turkey. All hotels operated on a year round basis. A total of 230 questionnaires were distributed to executive managers or human resource managers of each hotel. Questionnaires were then administered to employees working in supervisory or managerial positions. Completed questionnaires were then placed in container in the human resource department. Two hundred and five questionnaires, an $89 \%$ response rate, were obtained. The questionnaire was translated from English to Turkish than back again to English using the back-translation procedure by individuals fluent in both languages. Hotels ranged in size from 134 to 270 total employees with numbers of managers ranging from 14 to 50 .

\subsection{Respondents}

Table 1 presents the personal demographic and work characteristics of our sample $(\mathrm{n}=205)$. All worked fulltime and all had supervisory responsibilities. Most were male (56\%), were between 31 and 40 years of age $(83 \%)$, were married (54\%), without children (26\%), had bachelor's level degree educations $(67 \%)$, worked in their present jobs 5 years or less $(50 \%)$, and worked for their present hotels between 6 to 10 years $(43 \%)$, most were in lower management positions ( $56 \%$ ), worked between 46 and 50 hours per week (39\%), and worked in a variety of departments, most being in food and beverage and housekeeping ( $25 \%$ and $22 \%$, respectively).

\subsection{Measures}

All measures used in the research were translated from English to Turkish and back by members of the research team fluent in both languages using the back translation method.

Personal and work situation demographics

Personal and work setting characteristics were assessed by a number of single items. The former included: gender, age, current work status, current marital and parental status, and level of education. The latter included hours worked per week, organizational level, job tenure, organizational tenure, and whether respondent had supervisory duties. These items served as control variables in some of our analyses. 


\section{Self-efficacy}

Self-efficacy was measured by a ten item scale $(\alpha=.85)$ developed and validated by

Schwarzer and Jerusalem (1995). Respondents indicated how true they felt each item was as a description of themselves on a five point Likert scale ( 1 =not at all true, $3=$ moderately true, $5=$ exactly true). One item was "I can always manage to solve difficult problems if I try hard enough."

Workplace learning culture

Workplace learning culture was assessed by a 21 item scale $(\alpha=.96)$ developed by Marsick and Watkins (2003) and Yang, et. al, (2004), items falling at three levels: individual, work team, and organizational. Respondents indicated their agreement with each item on a six point Likert scale (1=Almost never, 6=Always). Sample items included "In my organization people help each other learn." "In my organization, teams/workgroups revise their thinking as a result of group discussions or information collected." and "My organization supports employees who take calculated risks." Scores on the three levels of workplace learning culture were positively and significant inter-correlated (average inter-correlation $=.44, \mathrm{p}<.001$ ), thus a composite measure was developed.

\begin{tabular}{|c|c|c|c|c|c|}
\hline Gender & $\underline{N}$ & $\underline{\%}$ & $\underline{\text { Age }}$ & $\underline{\mathrm{N}}$ & $\underline{\%}$ \\
\hline$\overline{\text { Male }}$ & $\overline{114}$ & $\overline{55.6}$ & $\overline{30}$ or less & $\overline{38}$ & $\overline{18.7}$ \\
\hline \multirow[t]{2}{*}{ Female } & 91 & 46.4 & $31-35$ & 64 & 31.1 \\
\hline & & & $36-40$ & 61 & 31.8 \\
\hline Parental Status & & & $41-45$ & 30 & 14.6 \\
\hline Children & 99 & 48.5 & 46 or more & 12 & 5.9 \\
\hline \multirow[t]{2}{*}{ No Children } & 105 & 51.5 & & & \\
\hline & & & Marital Status & & \\
\hline Department & & & Single & 94 & 45.9 \\
\hline Housekeeping & 11 & 5.4 & Married & 111 & 54.1 \\
\hline Food and beverage & 51 & 24.9 & & & \\
\hline Front office & 41 & 20.0 & Education & & \\
\hline Accounting & 26 & 12.7 & $\overline{\text { Elementary school }}$ & 2 & 1.0 \\
\hline Human resources & 44 & 21.5 & High school & 38 & 18.5 \\
\hline \multirow[t]{2}{*}{ Other } & 32 & 15.1 & Bachelor's degree & 137 & 66.8 \\
\hline & & & Master's & 27 & 13.2 \\
\hline Hours Worked & & & Doctorate & 1 & .5 \\
\hline 45 or less & 46 & 22.5 & & & \\
\hline $46-50$ & 80 & 39.0 & Organizational level & & \\
\hline $51-55$ & 56 & 27.4 & Lower management & 115 & 56.1 \\
\hline \multirow[t]{2}{*}{56 or more } & 23 & 11.3 & Middle management & 67 & 32.7 \\
\hline & & & Senior management & 23 & 11.2 \\
\hline \multicolumn{6}{|l|}{ Organizational tenure } \\
\hline 5 year or less & 80 & 38.9 & $\underline{\text { Job tenure }}$ & & \\
\hline $6-10$ years & 88 & 43.0 & $\overline{5 \text { year or less }}$ & 103 & 50.3 \\
\hline $11-15$ years & 32 & 15.7 & $6-10$ years & 88 & 42.9 \\
\hline 16 years or more & 5 & 2.5 & $11-15$ years & 13 & 6.4 \\
\hline
\end{tabular}

Table 1: Demographic Characteristics of Sample

\section{Workplace learning potential}

Workplace learning potential was measured by a twelve item scale $(\alpha=.89)$ developed and validated by Nilolova, et. al, (2014). Four dimensions were included, each measured by three items. Respondents indicated how applicable each item was to their current work situation on a five point Likert scale (1=not applicable at all; $5=$ completely applicable). Dimensions and a sample item of each included: learning through Reflection $(\alpha=.78)$ "In my work I am given the opportunity to contemplate about different work methods; Learning through Experimentation $(\alpha=.62)$. "In my job I can try different work methods even if that does not deliver any useful result." Learning from colleagues $(\alpha=.76)$ "My colleagues tell me if I make mistakes in my work" and Learning from Supervisor $(\alpha=.93)$ "My supervisor helps me see my mistakes as a learning experience." These four scales were positively and significantly inter-correlated (average inter-correlation $=.52, \mathrm{p}<.001$ ), so a composite measure was created.

\section{Perceived employability}

Perceived employability was assessed by nine items $(\alpha=.75)$ developed and validated by Wittekind, et. al, (2010). Respondents indicated their agreement with each item as they described themselves at work on a five point Likert scale ( $1=$ strongly disagree; $3=$ neither agree nor disagree, $5=$ strongly agree) One item was "If my organization offered me a possibility to obtain new work experiences, I would take it." Two aspects of employability were addressed: Employability orientation -5 items $(\alpha=.62)$ and employability activities -4 items 
( $\alpha=.72) \mathrm{S}$ Scores on the two scales were positively and significantly correlated $(r=.48, p<.001)$, thus a composite score was created.

Psychological empowerment

Psychological or personal feelings empowerment was measured by a twelve item scale $(\alpha=.87)$ developed and validated by Spreitzer (1996, 1995). This measure tapped four dimensions, each addressed by three items. Respondents indicated their agreement with each item on a seven-point Likert scale (1=very strongly disagree; $4=$ neutral, $7=$ very strongly agree). Meaning $(\alpha=.92$.) "The work I do is meaningful to me." Competence $(\alpha=.68)$ "I am confident about my ability to do my job." Self-determination $(\alpha=89)$ "I have significant autonomy in determining how I do my job." and Impact $(\alpha=.90)$ "My impact on what happens in my department is large". These four scales were positively and significantly inter-correlated (average inter-correlation $=.36, p<.001$ ), thus a composite measure was created.

Work outcomes

Three work outcomes were included.

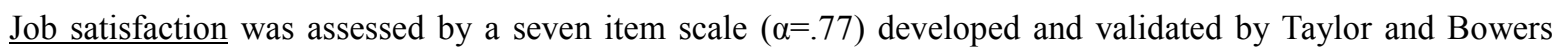
(1972). Respondents indicated their agreement with each item on a five-point Likert scale (1-very dissatisfied, $3=$ neither satisfied nor dissatisfied; $5=$ very satisfied. One item was "All in all, how satisfied are you with the persons in your work group?"

Service excellence

Quality of service provided by respondents to guests or clients was assessed by a six item scale $(\alpha=.81)$ developed and validated by Peccei and Rosenthal (2001) Respondents indicated their agreement with each item on a five-point Likert scale $1=$ strongly disagree; 3 -neither agree nor disagree, 5=strongly agree. An item was "I am strongly committed to service excellence".

Intent to quit was measured by two items $(\alpha=.61)$ used by Burke (1991). Respondents indicated "yes or no" for both items. One item was "Are you currently looking for a different job in a different organization?"

\section{Results}

Hierarchical regression analyses

Hierarchical regression analyses were undertaken in which predictor variables were entered in blocks in a specified order. In the first of two sets of hierarchical regression analyses, work outcome variables were separately regressed on three blocks of predictors. The first block of predictors, Personal demographics $(n=5)$ included gender, age, marital status, parental status and level of education. The second block of predictors Work situation characteristics $(n=4)$ included Job tenure, Organizational tenure, Organizational level, and Work hours. The third block of predictors included the measure of Self efficacy. When a block of predictors accounted for a significant amount or increment in explained variance on a given work outcome $(p<.05)$, individual measures within these blocks having independent and significant relationships with this work outcome $(\mathrm{p}<.05)$ were identified. In the second set of hierarchical regression analyses, two additional blocks were added. The fourth block included the measure of Workplace Learning Culture, and the fifth block included the measure of Workplace Learning Opportunities.

Personal and work situation characteristics and work outcomes

Table 2 presents the results of the first set of hierarchical regressions. The following comments are offered in summary. First, all three blocks of predictors accounted for a significant amount or increment in explained variance on Workplace Learning Culture. Managers who were single, at higher organizational levels, and indicating higher levels of self-efficacy reported higher levels of Workplace Learning Culture $(\mathrm{Bs}=-.17, .16$ and 41 , respectively)

Second, two blocks of predictors accounted for significant increments in explained variance on Workplace Learning Opportunities. Managers indicating higher levels of self-efficacy also reported more workplace learning Opportunities $(\mathrm{B}=.42)$.

Third, all three blocks of predictors accounted for a significant amount or increment in explained variance on Employability. Managers who were older, had lower levels of education, and indicated higher levels of selfefficacy also reported greater employability $(\mathrm{Bs}=.23,-.19$, and .44, respectively).

Fourth, all three blocks of predictors accounted for a significant amount or increment in explained variance on Job Satisfaction. Managers having longer organizational tenures and managers indicated higher levels of selfefficacy also reported greater Job Satisfaction ( $\mathrm{Bs}=.18$ an $\mathrm{d} .32$, respectively)

Fifth, all three blocks of predictors accounted for a significant amount or increment in explained variance on Psychological Empowerment. Managers indicated higher levels of self-efficacy also reported higher levels of Psychological Empowerment $(\mathrm{B}=.36)$ 
Sixth, two blocks of predicts accounted for significant increments in explained variance on perceptions of Quality of Service. Managers indicating higher levels of self-efficacy also reported higher levels of Quality of Service $(B=.51)$.

Finally, only one block of predictors accounted for a significant amount or increment in explained variance on Intent to quit. Managers indicating higher levels of self-efficacy also reported less intent to quit $(\mathrm{B}=.23$.)

Two more general observations are worth noting. First, most of the predictors accounted for significant amounts or increments in explained variance on these work outcomes. Second, levels of self-efficacy had significant relationships with all work outcomes included in the study.

Workplace learning culture, opportunities for workplace learning, and work outcomes

Table 3 presents the results of the second set of hierarchical regressions. The following comments are offered in summary. First, all five blocks of predictors accounted for significant amount or increment in explained variance on Employability. Older managers, managers having more education, manager indicating higher levels of self-efficacy, and managers describing higher levels of both workplace learning culture and workplace learning opportunities indicated higher levels of employability $(\mathrm{Bs}=.19, .19, .23, .30$ and 24, respectively).

Second, four of the five blocks of predictors accounted for a significant amount or increment in explained variance on job satisfaction. Managers having longer organizational tenures and managers describing higher levels of workplace learning culture also reported higher levels of Job Satisfaction (Bs=.17 and .58, respectively).

Third, four of the five blocks of predictors accounted for a significant amount or increment in explained variance on Psychological Empowerment. Managers having longer job tenures, those scoring higher on selfefficacy, and those describing a stronger workplace learning culture also indicated higher levels of psychological empowerment $(\mathrm{Bs}=.17, .28$ and 16 , respectively)

Fourth, three blocks of predictors accounted for significant increments in explained variance on perceptions of Quality of Service. Managers who were younger, and managers indicating higher levels of self-efficacy also reported more favorable perceptions of Quality of service ( $\mathrm{Bs}=-.21$ and .44, respectively).

Finally, three blocks of predictors accounted for significant increment $\mathrm{s}$ in explained variance on Intent to quit. Managers indicating stronger Workplace learning cultures and more opportunities for workplace learning indicated lower intentions to quit ( $\mathrm{Bs}=.20$ and .37 , respectively).

Four more general observations follow from these findings. First, predictor variables generally had significant relationships with these work outcomes. Second, managerial self-efficacy remained a significant predictor of Employability, Psychological Empowerment and Quality of Service perceptions. Third, Workplace Learning Culture had significant relationships with four of the five work outcomes. Fourth, Workplace Learning Opportunities had significant relationships with two work outcomes (Employability and Intent to quit).

\section{Additional observations}

Some broader observations can also be drawn from these findings. Self-efficacy emerged as an important individual difference characteristic associated with the empowerment measures. This suggested that individual attitudes, skills and feelings of personal confidence made employees more amenable and embracing of empowerment practices and were more likely to take advantage of the opportunity extended to them by higher levels of learning opportunities.

\section{Discussion}

The results of our research provide considerable support for the hypotheses underlying our work on several fronts. First, managerial self-efficacy emerged as a significant predictor of each work outcome. Second. Workplace learning culture, and associated workplace learning opportunities, also had significant relationships with some -but not all- of the work outcomes.

Our findings on the central role of personal efficacy (see Table 2) in being associated with both capitalizing on workplace learning processes and learning opportunities and sources, as well as being associated with valued work outcomes, was consistent with a growing body of research evidence (Luszcynska, et. al, 2005; Luszcynska, et. al, 2005; Maddox, 2002; Stajkovic and Luthans, 1998).

In addition, our findings on the benefits of creating workplace learning cultures and a greater number of learning sources and opportunities was also consistent with the work of others (Yang, et. al, 2004; Msarscik and Watkins, 2003; Nikolova, et. al,, 2014) 
Work outcomes

$\underline{\mathrm{R}}$

Workplace learning culture $(\mathrm{n}=199)$

Personal demographics

Marital status (-.17)

Education (-.17)

Work situation characteristics

Organizational level (.16)

Self-Efficacy (.41)

Learning opportunities ( $\mathrm{n}=203$ )

Personal demographics

Work Situation characteristics

Self-Efficacy (.42)

Employability ( $\mathrm{n}=201)$

Personal demographics

Age (.23)

Education (.19)

Work situation characteristics

Self-efficacy (.44)

Job satisfaction $(\mathrm{n}=202)$

Personal Demographics

Work situation characteristics

Organizational tenure (.18)

Self-efficacy (.32)

Psychological empowerment ( $\mathrm{n}=202$ )

Personal demographics

Work situation characteristics

Self-efficacy(.44)

Quality of service ( $\mathrm{n}=203$ )

Personal demographics

Work situation characteristics

Self-efficacy (. 51)

Intent to quit ( $\mathrm{n}=203$ )

Personal demographics

Work situation characteristics

$\underline{\text { Self-efficacy (.23) }}$

$\underline{\mathrm{R}^{2}}$

$\underline{\Delta \mathrm{R}^{2}}$

$\underline{P}$

.14

.14

.07

.13

.001

.34

.09

.12

.25

.09

.03

.13

.01

NS

.001

.41

.17

.001

.47

.60

.22

.05

.14

.001

.001

.32

.50

.10

.10

.07

.001

.01

.25

.08

.001

.38

.001

.06

.10

.01

.21

.26

.57

$$
.04
$$

.04

$$
.09
$$

NS

.00

$.19 \quad .001$

$\begin{array}{llll}.13 & .02 & .02 & \text { NS } \\ .22 & .05 & .03 & \text { NS } \\ .29 & .08 & .03 & .01\end{array}$

Table 2: Personal and Work Situation Characteristics and Work Outcomes

\subsection{Practical Implications}

We have come to better understand factors associated with increased levels of workplace learning (Crouse, et. al, 2011; Hicks, et. al, 2007; Lohman,2009, 2006, 2005) for example Crouse, et. al, (2011) review the literature on workplace learning strategies, barriers and facilitators. Workplace learning strategies refer to ways that employees acquire new knowledge, skills and attitudes. Crouse and her colleagues grouped learning strategies into nine categories: taking courses, and programs, doing new tasks at work, working with others, e-learning, watching others, by trial and error, reading and conducting research, reflecting on one's actions, and trying to repeat what was based on learning. Barriers to learning were things that prevented, interrupted, impeded and stopped learning for moving forward. They identified nine barriers to workplace learning: Learning lack of resources, limited access to training and equipment, technological constraints, personal factors (e.g., fear of failure, low motivation), interpersonal constraints (others unwilling to help), workplace culture constraints (culture does not support learning), too much and too rapid change, little power to make decisions), and limited value in formal training offerings (poor instructors, too much to learn). Facilitators were things that motivated, sustained and heightened learning. They identified six categories of facilitators: the role and help of others, training from others, job-related experiences and needs, increased resources, work cultures that support learning, and personal attributes (being able to ask for help, being open to new ideas). Organizations need to increase facilitating factors and reduce barriers to workplace learning. 
Work Outcomes

Employability $(\mathrm{n}=198)$

Personal demographics

Age (.19)

Education (.19)

Work situation characteristics

Self-efficacy(.23)

Workplace learning culture(.30)

Workplace learning opportunities (.24)

\section{$\underline{\mathrm{R}}$}

Job Satisfaction $(\mathrm{n}=197)$

Personal demographics

Work situation characteristics

Organizational tenure (.17)

Self-efficacy

Workplace learning culture (.58)

Workplace learning opportunities

Psychological empowerment ( $\mathrm{n}=198$ )

Personal demographics

Work situation characteristics

Job tenure (.17)

Self-efficacy (.28)

Workplace learning culture (.16)

Workplace learning opportunities

Quality of service ( $\mathrm{n}=199)$

Personal demographics

Work situation characteristics

Self-efficacy (.44)

Workplace learning culture

Workplace learning opportunities

Intent to quit ( $\mathrm{n}=199)$

Personal demographics

Work situation characteristics

Self-efficacy

Workplace learning culture (.30)

Workplace learning opportunities (.37)

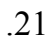

.35

.57

.58

.59

\section{3}

.21

.29

.43

.51
.42

.62

.71

.73

$\underline{\mathrm{R}^{2}}$

$\underline{\Delta \mathrm{R}^{2}}$

$\underline{P}$

.001

.05

.001

.001

.001

.001

.01

.001

$\begin{array}{lll}.51 & .27 & .001 \\ .52 & .01 & \text { NS }\end{array}$

$\begin{array}{lll}.51 & .27 & .00 \\ .52 & .01 & \text { NS }\end{array}$

.73

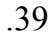

.15

.15

.001

.46

.21

.06

.01

.56

.32

34

.35

.001

.01

$\begin{array}{ll}.01 & .01 \\ .01\end{array}$

\section{.04}

.12

$$
.33
$$

$\begin{array}{ll}.04 & \text { NS } \\ .08 & .01 \\ .21 & .001 \\ .01 & .05 \\ .01 & \text { NS }\end{array}$

Table 3: Workplace Learning Culture, Workplace Learning Opportunities and Work Outcomes

Workplaces interested in increasing workplace learning need to first position this as an important part of their business strategy and then communicate this throughout their organizations. They then need to develop human resource management policies and practices, provide resources (e.g, technology, time, space to think and talk), to support this priority. Employees should receive training in the range of informal learning strategies that are possible.

Workplaces interested in developing and support a learning culture need to develop cultures of trust, learning and innovation, increase levels of managerial and supervisory support, increase individual confidence in sharing useful knowledge, and address cross cultural/international issues (Teare, 1998; Teasre and Rayner, 2002). The good news is that there are established and well validated measures of workplace learning culture (Marsick and Watkins, 2003) as well as of workplace learning opportunities and sources (Nikoloava, et. al, 2014) that could be used to diagnose where they currently stand in terms of workplace learning possibilities and initiate cultural change initiatives.

Organizations should also undertake efforts to increase employee self-efficacy. Maddox (2002) writes that selfefficacy beliefs develop through experience over time. Self-efficacy can be increased by having individuals evaluate their own performance experiences. By encouraging individuals to take small risks that could lead to small successes, by seeing one's successes as having a positive impact, and by creating situations where individuals experience success based on their own efforts. 


\subsection{Future Research Directions}

Our understanding of the benefits of workplace learning would be increased by including assessments of ways in which informal learning outcomes have been transferred to actual job performance. In addition, examining ways that formal training and informal workplace learning can augment each other would be useful.

\section{References}

- Argyris, 2003. “A life full of learning”, Organizational Studies, 24, p. 1178-1197.

- Argyris, 1997. "Double loop learning in organizations”, Harvard Business Review, 55, p. 115-124.

- Baum, 2007. "Human resources in tourism: Still waiting for change”, Tourism Management, 28, p. 13831399.

- Bowen and Lawler, 1995. "Empowering service employees", Sloan Management Review, 36, p. 73-84.

- Burke, 1991. "Early work experiences of female and male managers and professionals: Reasons for optimism?”, Canadian Journal of Administrative Sciences, 8, p. 224-230.

- Crouse, Doyle, and Young, 2010. "Workplace learning strategies, barriers, facilitators and outcomes: A qualitative study among human resource management professionals "Human Resource Development International,14,p.39-55

- DeCuyper and De Witte, 2011. "The management paradox: self-rated employability and organizational commitment and performance", Personnel Review, 40, p. 152-172.

- Denton, 1998. Organizational learning and effectiveness. Routledge, London.

- Duman and Tosun, 2010. "Current developments in Turkish tourism", Anatolia: An International Journal of Tourism and Hospitality Research, 21, p. 5-9.

- Gokovali, 2010. "Contribution of tourism to economic growth in Turkey", Anatolia: An International Journal of Tourism and Hospitality Research, 21, p. 139-153.

- Gunduz and Hatemi-J, 2005. "Is the tourism-led growth hypothesis valid for Turkey?" Applied Economics Letters, 12, p. 499-504.

- Hicks, Bagg, Doyle, and Young, 2007. “Canadian accountants: Examining workplace learning”, Journal of Workplace Learning, 19, p. 61-77.

- Kusluvan, 2003. Managing employee attitudes and behavior in the tourism and hospitality industry. Nova Science, New York.

- Kusluvan, Kusluvan, Ilhan, and Buyruk, 2012. "A review of human resources management issues in the tourism and hospitality industry”, Cornell Hospitality Quarterly, 51, p. 171-214.

- Law and Ngai, 2008. "An empirical study of the effects of knowledge sharing and learning behaviors on firm performance”, Expert Systems with Applications, 34, p. 2342-2349.

- Li, Gray, Lockwood, and Buhalis, 2011. "Learning about managing the business in the hospitality industry", Human Resource Development Quarterly, 24, p. 525-559.

- Lohman, 2009. "A survey of factors influencing the engagement of information technology professionals in informal learning activities”, Information Technology, Learning, and Performance Journal, 25, p. 43-53.

- Lohman, 2006. "Factors influencing teachers' engagement in informal learning activities", Journal of Workplace Learning, 18, p. 141-156.

- Lohman, 2005. "A survey of factors influencing the engagement of two professional groups in informal workplace learning activities", Human Resource Development Quarterly, 16, p. 512-527.

- Lopez, Montez Peon, and Vazquez Ordas, 2006. "Human resource management as a determining factor in organizational learning”, Management Learning, 37, p. 215-230.

- Luszczynska, Gutierrez-Dona, and Schwarzer, 2005. "General self-efficacy in various domains of human functioning: evidence from five countries”, International Journal of Psychology, 40, p. 80-89.

- Luszczynska, Schoklz, and Schwarzer, 2005. "The General Self-Efficacy Scale: Multicultural validation studies. Journal of Psychology, 139, p. 439-457.

- Maddux, 2002. Self-efficacy: The power of believing you can. In C. R. Snyder and s. J. Lopez (eds.) Handbook of Positive Psychology. Oxford University Press, New York. p. 27-287.

- Magnini, 2009. "An exploratory investigation of the real-time training modes used by hotel expatriates", International Journal of Hospitality Management, 28, p. 513-518.

- Marsick and Watkins, 2003. "Demonstrating the value of an organization's learning culture: The dimensions of the Learning Organization Questionnaire", Advances in Developing Human Resources, 5, p. 132-151. 
- Nauta, van Vianen, van der Heijden, van Dam, and Willemsen, 2009. "Understanding the factors that promote employability orientation: The impact of employability culture, career satisfaction, and role breadth self-efficacy", Journal of Occupational and Organizational Psychology, 82, p. 233-251.

- Nikolova, Van Ruysseveldt, De Witte, and Syroit, 2014. "Work-based learning: Development and validation of a scale measuring the learning potential of the workplace (LPW)", Journal of Vocational Behavior, 84, p. $1-10$.

- Nonaka, 1991. "The knowledge creating company", Harvard Business Review, 69, p. 96-104.

- Peccei and Rosenthal, 2001. "Delivering customer-oriented behavior through empowerment: An empirical test of HRM assumptions”, Journal of Management Studies, 38, p. 833-857.

- Rothwell and Arnold, 2007. "Self-perceived employability: Dimensions and validation of a scale" Personnel Review, 37, p. 23-41.

- Salas and Von Glinow, 2008. Fostering organizational learning: Creating and maintaining a learning culture. In R. J. Burke \& C.L. Cooper (eds), Building more effective organizations: HR management and performance and practice. Cambridge University Press, Cambridge. p. 207-227.

- Schwarzer and Jerusalem, 1995. Generalized self-efficacy scale. In J. Weinman, S. Wright \& M. Johnston (eds.) Measures in health psychology: A user's portfolio. Causal and control beliefs. Nelson Windsor, p.35-37.

- Spreitzer, 1996. "Social structural characteristics of psychological empowerment", Academy of Management Journal, 39, p. 483-504.

- Spreitzer, 1995. "Psychological empowerment in the workplace: dimensions, measurement, and validation", Academy of Management Journal, 38, p. 1442-1465.

- Stajkovic and Luthans, 1998. "Self-efficacy and work-related performance: A meta-analysis", Psychological Bulletin, 124, p. 240-261.

- Taylor and Bowers, 1972. Survey of organizations: A machine-scored standardized questionnaire instrument. MI.: Institute for Social Research, Ann Arbor.

- Teare, 1997. "Enabling organizational learning”, International Journal of Contemporary Hospitality Management, 9, p. 3125-324.

- Teare and Rayner, 2002. "Capturing organizational learning”, International Journal of Contemporary Hospitality Management, 14, p. 354-360.

- Tracey and Hinkin, 1994. "Transformational leaders in the hospitality industry", Cornell Hotel and Restaurant Administration Quarterly, 35, p. 18-24.

- Van Dam, 2004. “Antecedents of employability orientation”, European Journal of Work and Organizational Psychology, 13, p. 29-51.

- Van der Heijde and van der Heijden, 2006. "A competence-based and multidimensional operationalization and measurement of employability", Human Resource Management, 45, p. 449-476.

- Van der Heijden, Boon, van der Klink, and Meijs, 2009. "Employability enhancement through formal and informal learning: An empirical study among Dutch non-academic university staff members", International Journal of Training and Development, 13, p. 19-37.

- Van der Heijden, de Lange, Demeroutii, and van der Heijde, 2009. “Age effects on the employability-career success relationship", Journal of Vocational Behavior, 74, p. 156-164.

- Wilhelm, 2006. "Learning organizations", Leadership Excellence, 23, p. 17-30.

- Wittekind, Raeder, and Grote, 2010. "A longitudinal study of determinants of perceived employability", Journal of Organizational Behavior, 31, p. 566-586.

- Yang, 2007. "Knowledge sharing: Investigating appropriate leadership roles and collaborative culture", Tourism Management, 28, p. 530-543.

- Zemke and Schaaef, 1989. The service edge: 101 companies that profit from customer care. New American Library, New York. 